\title{
Article Title: The role of sustainability in HE and the GEES disciplines; recommendations for future practice.
}

\begin{abstract}
Sustainability is becoming a key component of many HE curricula. However, questions as to what sustainability is and how it can be embedded within subject specific curriculum are difficult to answer. Focussing on existing pedagogic scholarship in this area and by drawing on experiences from my own institution, this article discusses how the GEES subjects are addressing sustainability in the curriculum. It provides both conceptual framing on the evolution of the GEES subjects in relation to sustainability and offers some practical examples of how different approaches to sustainability might be used in teaching, including challenging disciplinary perspectives and introducing interdisciplinary working around global challenges. It concludes with recommendations for how sustainability might be embedded in the curriculum in practice.
\end{abstract}

Keywords: sustainability, HE, GEES disciplines, curriculum change

\section{Introduction}

Higher Education Institutes (HEI's) are engaging with a range of sustainability issues. For instance, over the last decade a rhetoric around 'campus sustainability' has emerged, driven both internationally, (eg. the United Nations, Rio+20 meeting in 2012, highlighted the importance of sustainability in education), and up until recently in the UK, HEFCE driving the agenda through their policy framework on sustainable development in HE (HEFCE, 2014). Campus sustainability is generally focussed on the physical, educational (teaching, curricula, research) and institutional dimensions, or - how to mainstream practices around sustainability into Universities. 
This article focuses on how sustainability is embedded within the curriculum for Geography, Earth and Environmental Science (GEES) ${ }^{1}$ and using existing literature, explores how sustainability is differently shaping the ontological practices of disciplines within GEES. This article aims to discuss the multiple meanings of sustainability and asks the question - what is learning for sustainability? This is followed by an exploration of the how sustainability is being embedded in the GEES curricular, and further reflect on how sustainability is shaping or changing aspects of the GEES disciplines. Building on this, the latter section of this article will provide practical examples on how to include learning for sustainability and provide future recommendations, drawing on the pedagogic literature and analysis of the curricular.

\section{What is learning for Sustainability?}

One of the early definitions of Sustainability appeared in the Brundtland Commission report (1987), that described sustainability as;

"Meeting the needs of the present without compromising the needs of the future". (Brundtland Commission, 1987 p.7)

Evolving from this broad level definition, the notion of sustainability is now considered to have three main pillars; environmental, economic and social. The concept of sustainability is also closely linked to sustainable development and building on that, education for sustainable development (ESD). With an international interest, sustainable development has been discussed widely within global political circles and is cited as a 'globally accepted concept to guide interactions between nature and society that calls for a paradigm change at all levels including education' (Disterheft et al., 2013, p.4). Indeed it has been argued that educators and HEI's have a greater influence than any other sector of society and have a moral

\footnotetext{
${ }^{1}$ It is acknowledged that GEES subjects can also include Biosciences, however for the purpose of this paper GEES are defined traditionally as Geography, Earth and Environmental Sciences.
} 
obligation to do so given their position to shape the next generation of future leaders and influencers (Croog et al., 2016).

However, the social, economic and environmental pillars of sustainability have been criticised for their anthropocentric focus. Contestations of the sustainability concept question what it actually is that is being sustained and why (Boer, 2013). Furthermore, critical perspectives on sustainable development question the idealised notion of 'development', that is generally framed using western rhetoric. This leads to the assumption that developing countries should align with westernised understandings of development processes and growth (Redclift, 1991) and critiques of this approach chime readily with growing calls for a decolonisation of the University and curriculum (eg. for example see Noxolo, 2017, Mbembe, 2016). Different institutional, ideological and academic perceptions have led to an evolution of the concept, and now a fourth and fifth pillar have been included to reflect this; the institutional and cultural pillars of sustainability (eg. see Burford et al., 2013, Disterheft et al., 2013).

Given this divergence in defining what sustainability and sustainable development should be, how do we then consider what learning for sustainability should be? (Pearson et al., 2005). Reflecting on this in the HEI setting, Cortese (2003 in Disterheft, et al., 2013) identifies four dimensions of the university system; these are education, research, university operations and the external community. Lozano (2006) builds on this by adding a fifth; assessment and reporting. However, sustainability is currently reflected or positioned across these dimensions with a heavy emphasis being placed on environmental issues, and less on the nonmaterialistic aspects of sustainability eg. social, cultural and ethical questions. As Disterheft et al., (2013) comments, if we are to use the education system and HEI setting to help deliver a paradigm shift in policies and sustainability discourse more broadly, we must also debate the learning objectives, pedagogies and competencies needed to enable such a transition to 
take place. This includes considering the different ideological and academic viewpoints to give a holistic and meaningful representation of sustainability within a given HE institution and arguable, within the HE dialogue more broadly.

Education for sustainable development (ESD) can also take on different meaning depending on the university setting, defined by a particular HEI's ethos and the frameworks and political subtexts in which it operates. This could be for instance, the positioning of arguments for and against sustainable economic growth (Higgitt, 2013). This subtext might be defined by the wider socio-political and economic contexts of a particular national and regional context in which the particular HEI sits, and this will also shift and evolve overtime. Furthermore, it's important to recognise that students across not only different disciplinary areas, but also from different countries and cultures, will hold different environmental values (Higgitt, 2013). This will inform perceptions on the ways in which 'sustainability' should be defined and therefore embedded within their curriculum. Within this broader context, the following will focus on the UK context with observations and practical aims from the GEES curriculum.

\section{Sustainability in the curriculum; an exploration of GEES}

Geography, Earth and Environmental Sciences (GEES) have been described as natural bedfellows with regards to sustainability, given that GEES subjects are intrinsically based on exploring human-nature interactions (Chalkley et al., 2010). For instance, the QAA Subject benchmark statement for Geography (2014) states under section 3 'Subject knowledge and Understanding' that Geographers should:

"understand the place of their discipline in contributing to a holistic perspective on the natural and human worlds, and processes that is distinctive of Geography compared to other disciplines. They understand the complex relationship between natural and human aspects of 
environments and landscapes and appreciate the geographical meaning of concepts encompassing:

- Knowledge of environments being the result of natural processes

- Knowledge of environments and landscapes as the result of human activity

- A critically informed understanding of ways of representing and interpreting the world."

(QAA. 3.2, Geography, 2014)

The term 'sustainability' is used scarcely within the QAA Subject benchmark statement for Geography, however the themes and focus of the discipline are synonymous with the broader conceptualisation of what sustainability should mean. Indeed, it could be argued that Geography is particularly well placed to tackle the challenge of sustainability given that the discipline of Geography includes and goes beyond understandings of the physical environment to include critical perspectives of the social, cultural and political. This is seen as a defining feature of the discipline, and frames sustainability as one of a number of contexts with which to critically apply geographical concepts to better understand the human and natural world:

"Geographers are aware of the relevance of geographical concepts, techniques and expertise to problem solving, wealth creation, poverty reduction and improving the quality of life and well-being, for example, in the context of climate change, urban and rural planning, hazard assessment, sustainability and environmental management. However, awareness of this is balanced by recognition of their limitations, a critical understanding of their broader social, political and environmental contexts and the ethical implications of their application."

(QAA 3.15, Geography, 2014) 
This enables the discipline to match up to the aforementioned critiques that sustainable development can sometimes face of being too environmentally focussed, without considering social, cultural and ethical dimensions of the challenge.

The QAA Subject benchmark for Earth Sciences, Environmental Sciences and Environmental Studies, referred to in the benchmark collectively as the ES3 (2014), takes a different approach, foregrounding sustainability as a key part of the disciplinary curriculum. For instance, the benchmark states:

"Sustainability is a fundamental part of many subject areas associated with ES3 and is built into most curricula. This aspect of ES3 may also influence curricula in other subject areas, as the emphasis grows on the importance of providing all graduates with the necessary skills to promote a sustainable society. Sector agencies have worked together to produce guidance for higher education providers in implementing education for sustainable development across subject areas"

(QAA 1.5, ES3, 2014)

The benchmark goes on further to describe the shifting values of the discipline since the last QAA benchmark statement in 2007 , particularly around sustainability and interdisciplinarity:

"The first review group (2007) made relatively minor amendments to the original benchmark statement to focus on shifting values within the area, including greater emphasis on:

- sustainability with particular emphasis on the environmental context of sustainability

- employability

- the links to and roles of professional bodies

- interdisciplinarity and problem solving

- provision of content statements to accompany performance levels 
- clarity on the terrain encompassed by programmes in Earth sciences, environmental sciences and environmental studies."

(QAA 2.2, ES3, 2014)

Although the QAA ES3 benchmark does not define sustainability, it does state early on in the statement that it refers to sustainability particularly in the environmental context. Comparing aspects of the two benchmarks from within the GEES disciplines, Geography, and Earth \& Environmental Science, it is evident that even within these closely aligned disciplines, a difference in positionality or approach can be observed with regard sustainability and curriculum development. It also heeds two important lessons to reflect on when thinking about the way in which sustainability is, or is not embedded in the curriculum. One describes its intentions with regard sustainability and sustainable development explicitly, while the other focussed on the core themes and concepts inherent to its discipline. This does not mean that the latter neglects the challenges observed in this area, on the contrary, it provides a critical stance with which to observe and understand human-environment interactions more wholly, of which sustainability emerges as one concept with which to understand the broader framing of human-environment interactions.

\section{Conceptualising curriculum change in the context of sustainability.}

A curriculum helps shape educational frameworks, formed around 'knowledge, action and self' with knowledge fields in particular shaping disciplinary identities (Barnett et al., 2001). Values and practices within disciplines can also shape knowledge fields to varying degrees. For instance, epistemological differences, can alter the weighting of 'knowledge, action, self' within a knowledge field and discipline (ibid). Barnett et al., (2001) describes these disciplinary domains in detail; (1) The Knowledge domain - this being the structure of the knowledge field taking shape (eg. Barnett et al., uses the example of history becoming more 
sociological). This domain also relates to the emergence of new topics or sub-fields within a discipline (2) The Action domain - this entails the competency or skills required to become a specialist within a particular discipline, sometimes referred to as knowledge in use and (3) The Self domain - this relates to the educational identity of a particular subject or disciplinary area.

If we consider the Knowledge domain in the context of GEES subjects, evidence from the QAA benchmark would suggest that particularly for ES3 subjects, sustainability is having a significant impact on the way the discipline is shaped, leading to a greater emphasis on sustainable development and working in an interdisciplinary manner. This can be observed in the QAA Subject benchmark statements for ES3, as highlighted above, and also through calls from significant voices within the discipline encouraging not only for more emphasis on sustainability but for closer collaboration with the social sciences. For instance, Iain Stewart, (amongst others eg. See Schlosser and Pfirman, 2012, writing on Earth Science for sustainability) has been very prominent in this area writing a number of high impact pieces on the topic including a correspondence piece for Nature Geoscience on 'Sustainable geoscience' (Stewart, 2016). In his work Stewart (2016) encourages geologists in particular to be more involved in sustainable development and to work more readily with the critical social sciences to better understand human-environment relations. Stewart and Gill (2017) also call for sustainability to be better embedded within the geoscience curriculum so as to 'prepare geoscientists for their evolving future role in the coming of age of clean energy, resource constraints and smart cities' (p.171). He goes on to note 'the most substantive way to integrate sustainability concepts into Earth sciences training will be to design and develop postgraduate courses that exploit interdisciplinary alliances within universities to establish more holistic Earth science perspectives to pressing societal concerns' (Stewart and Gill, 2017 p, 171) (for reference, geoscience is part of the ES3 disciplines described above). What 
this indicates is that the emergence of sustainability as a concept is shifting the knowledge domain for ES3 disciplines and the subsequent curricula it lends itself to. This shift is also influential for the Self-domain, or the educational identity of the discipline, given this greater emphasis on working in a more interdisciplinary manner and this will impact how the curriculum is developed and taught in practice.

The following sections will provide two practical examples of how to meet this challenge. The first discusses a teaching-led exercise that uses the role of experiential and active learning for sustainability, and the second presents a module example from a particular University's GEES curriculum. This example does not focus on the curriculum in its entirety (this is out of scope for this article) but does present a practical application of how to embed a module within the wider GEES curriculum eg. one that can be taken by human and physical geographers, and Earth and Environmental science students, and that tries to reflect disciplinary ontology and shift in disciplinary focus on sustainability, including encouraging interdisciplinary learning.

\section{The role of experiential and active learning for sustainability}

When considering education for sustainable development McCloskey (2014) discusses active learning as a means to enable new skills, values and knowledge that will go on to influence actions and social change. McCloskey (2014, p.5-6) further goes on to state 'development education aims to deepen understanding and encourage action towards a more just and sustainable world...to work in collaboration with people from different backgrounds, recognising cultural and social differences'. Also a key feature in common for Geography, the ES3 disciplines and education for sustainability, is that of experiential learning. As an example, the Geography QAA benchmark states: 
"Experiential learning contributes significantly to curiosity and enquiry about human and physical environments, the development of discerning observation and measurement, and recognition of the importance of scale. Graduates understand the evolution and significance of the distinctiveness of places and environments, including different approaches to their interpretation, and a parallel understanding of the role of spatial linkages in social and physical processes"

(QAA 2.2 Geography, 2014)

This is recognised through the many skills-based and field-based modules and learning activities that Geographers (both Human and Physical) and Earth and Environmental Science students take and reflect on as an integral part of the curriculum.

While GEES subjects offer many opportunities for experiential learning on human-nature interaction, DuPuis and Ball (2013) offer an example of how to specifically teach an understanding of different social, cultural and world-view perspectives on sustainability. In their paper they discuss how to teach about sustainability as a process and highlight different ways of knowing as subjective, discursive, codifed and practice-based. DePuis and Ball (2013, p. 70) discuss a teaching activity that encourages students to think reflexively about their own framing and situated knowledge compared to other students in the class. The students are given a set of objects to rank individually in terms of their 'sustainability', each student is then asked to explain to the others why they have ranked them in a particular order. They are not given a definition of sustainability and if they ask for one, they are told to use their own concept or understanding of what sustainability is. They then share with the other students their ranking and rationales. The purpose of the exercise is for students to see how using their own criteria based on their own individual tacit and explicit knowledge or particular framing, can lead to very different results. After sharing knowledge with each 
other, they then have the opportunity to change their ranking of objects should they wish to do so. This exercise no only demonstrates a good pedagogic tool for introducing the concept of sustainability into a particular teaching activity, it also highlights the value for students identifying their own positionality, developed through their own explicit (disciplinary) and tacit knowledge, to then engage in dialogue and understanding around other world-views. The following example will focus more directly on the curriculum in practice, introducing a module example that addresses different perspective on sustainability across the GEES subjects.

\section{The Curriculum in Practice}

The department from which this example is taken, is home to multiple disciplines that research and teach on various aspects of the environment. These include Geography, Earth and Environmental Science and additionally, Ecology and Conservation and Biology.

To try to introduce students at an early stage to different disciplinary framings of sustainability, students across the GEES cohort undertake a core first year module called 'Global Environmental Challenges'. This module demonstrates the need for interdisciplinary dialogue to help solve global challenges, of which sustainability in its many guises appears. The aim of the module is to 'gain a clearer understanding of the connections between social, environmental and biotic processes and explore possible solutions for key environmental issues'. Research-led teaching is used to design lectures on global challenges. For example two of the themes covered are (amongst other things); (1) the Anthropocene, which are taught by both earth scientists and social scientists, and (2) anthropogenic emissions and mitigation measures, which are taught by physical geographers, an engineering lecturer and social and economic geographers. In this particular module, the themes addressed are readily linked to the Sustainable Development Goals (SDG's) and encourage discussion and debate on 
particular approaches to these challenges, as well as one's own preconceived ideas on what sustainability is and how it should be addressed. This enables the students to not only think about the ways in which sustainability are being addressed from different perspective across GEES, and critically evaluate those approaches, it also encourages students at an early stage in their academic career, to recognise the importance of working in an interdisciplinary manner. This aligns with this percieved shift in the Knowledge domain for GEES subjects on sustainability, specifically for ES3 subjects.

Students are also taught core modules that teach key principles, concepts and skills related to their particular discipline, however they are encouraged in the early stages of their degree to consider the value of other disciplinary perspectives in addition to their own. In this particular department, students are able to build on this going into Part 2 (years 2 and 3) with the opportunity to share or choose optional modules from other disciplines within theGEES subjects.

Encouraging students and scholars more broadly, to step away from the label a discipline gives and to work collectively on themes around key global challenges, has both is merits and difficulties, including the lack of educational identity that can ensue. The need to maintain the 'Self' domain (related to the educational identity of a subject or discipline) is equally important as reflecting the changing role of sustainability in shaping the Knowledge domain of a discipline. Therefore learning outcomes still need to tie strongly to a disciplinary perspective (for the Self domain) and this might vary amongst disciplines, whilst also acknowledging how discipline knowledge is shifting with respect to sustainability.

\section{Recommendations for the GEES disciplines}

Based on the exploration of the literature around sustainability, education for sustainability and specifically the GEES disciplines, the following general recommendations are made; 
- As highlighted in this article, there is diversity amongst disciplines as to what sustainability is and how explicitly it should be embedded in the curriculum eg. there is even diversity in the closely aligned GEES subjects such Geography and Earth and Environmental Science Subjects, as demonstrated in the QAA benchmark statements. Therefore, there needs to be an element of autonomy for disciplines to teach their particularly disciplinary perspective of what 'sustainability' should mean, and in doing so, encourage a more global and holistic perspective

- There is a need to encourage interdisciplinarity, to help demonstrate how different ontologies can work together to address global challenges on sustainability, however caution should be taken to keep balance of the core ontologies that define disciplines.

- Evaluating learning outcomes for this is difficult, and should be reflective of a particular disciplines positionality (including contestations of the sustainability concept)

- These ontologies are also evolving. Using research-led teaching, as well as periodic review should help in keeping track of this Eg. The emergence of the Anthropocene concept is an example of this.

- Embrace diversity of approach and encourage debate - this will help engender cultural change.

This guidance is in some way presented here with caution. There are strong arguments against embedding sustainability within the HEI curriculum explicitly, given the assumption that dictating it as a necessity, indoctorine's students to one particular (and some would say political) way of thought. HEI curriculum, it is suggested, should be more about teaching students to think critically and make up their own minds and positionality on the concept, and enabling rather than inhibiting the University's autonomy for free speech (Jones et al., 2010). 
Notwithinstanding these arguments, what has been presented in this article, particularly for the GEES subjects, supports in principle, sustainability being a part of the curriculum. Moreover, it suggests using this to encourage debate and teach critiques of the overarching concept enabling us to think beyond environmental aspects to include different social, cultural and political perspectives. Thus enabling our graduates to appreciate other disciplinary and world-view perspectives as well as recognising the aspects of their own lives and educational journey that have shaped these.

NB. For those particularly interested in exploring sustainability in the curriculum (including beyond GEES subjects) I would recommend two key texts:

1. Caeiro, S., Leal Filho, W., Jabbour, C. and Azeiteiro, U., (2013). Sustainability assessment tools in higher education institutions: mapping trends and good practices around the world. Cham: Springer International Publishing : Imprint: Springer.

2. Sterling, S. ed., (2010). Sustainability education: Perspectives and practice across higher education. Taylor \& Francis.

\section{References}

Barnett, R., Parry, G. and Coate, K., (2001). Conceptualising curriculum change. Teaching in Higher Education, 6(4), pp.435-449.

Boer P. (2013) Assessing Sustainability and Social Responsibility in Higher Education Assessment Frameworks Explained. In: Caeiro S., Filho W., Jabbour C., Azeiteiro U. (eds) Sustainability Assessment Tools in Higher Education Institutions. Springer, Cham. 
Brundtland Commission (1987) Report of The World Commission on Environment and Development: Our Common Future. Oxford University Press.

Burford, G., Hoover, E., Velasco, I., Janoušková, S., Jimenez, A., Piggot, G., Podger, D. and Harder, M.K., (2013). Bringing the "missing pillar" into sustainable development goals: Towards intersubjective values-based indicators. Sustainability, 5(7), pp.3035-3059.

Chalkley, B., Blumhof, J., Vala Ragnarsdottir, K.(2010) Geography, Earth and Environmental Sciences: A suitable home of ESD? In; Sterling, S. ed., Sustainability education: Perspectives and practice across higher education (pp.93-107). Taylor \& Francis.

Cortease (cited in) Disterheft, A., Caeiro, S., Azeiteiro, U.M. and Leal Filho, W., (2013).

Sustainability science and education for sustainable development in universities: a way for transition. In Sustainability Assessment Tools in Higher Education Institutions (pp. 3-27). Springer International Publishing.

Croog, R., (2016). Campus sustainability at the edges: Emotions, relations, and bio-cultural connections. Geoforum, 74, pp.108-116.

Disterheft, A., Caeiro, S., Azeiteiro, U.M. and Leal Filho, W., (2013). Sustainability science and education for sustainable development in universities: a way for transition. In Sustainability Assessment Tools in Higher Education Institutions (pp. 3-27). Springer International Publishing.

DuPuis, E.M. and Ball, T., (2013). How not what: teaching sustainability as process. Sustainability: Science, Practice, \& Policy, 9(1).

HEFCE (2014) Sustainable Development Framework http://www.hefce.ac.uk/workprovide/Framework/ (accessed 16/01/2018)

Higgitt, D (2013) Introduction: Approaching the UN Decade for Education for Sustainable Development. Prospects and Challenges. In; Chalkley, B., Haigh, M. and Higgitt, D. eds., Education 
for sustainable development: papers in honour of the United Nations Decade of Education for Sustainable Development (2005-2014). Routledge.

Jones, P., Selby, D., Sterling, S, (2010) Introduction In; Sterling, S. ed., Sustainability education: Perspectives and practice across higher education (pp.1-16). Taylor \& Francis.

Lozano, R., (2006). Incorporation and institutionalization of SD into universities: breaking through barriers to change. Journal of cleaner production, 14(9), pp.787-796.

McCloskey, S (2014) Introduction: Transformative Learning in the Age of Neoliberalism. In; McCloskey, S. ed., Development Education in Policy \& Practice (pp. 1-18). Palgrave Macmillan. Mbembe, A., 2016. Decolonizing the university: New directions. Arts and Humanities in Higher Education, 15(1), pp.29-45.

Noxolo, P., 2017. Introduction: Decolonising geographical knowledge in a colonised and re- colonising postcolonial world. Area, 49(3), pp.317-319.

Pearson, S., Honeywood, S. and O’Toole, M., (2005). Not yet learning for sustainability: The challenge of environmental education in a university. International Research in Geographical \& Environmental Education, 14(3), pp.173-186.

QAA Subject benchmark statement; Earth Sciences, Environmental Sciences and Environmental Studies (ES3) (2014) UK Quality code for Higher Education http://www.qaa.ac.uk/en/Publications/Documents/SBS-earth-sciences-14.pdf (accessed 16/01/2018). QAA Subject benchmark statement; Geography (2014), UK Quality code for Higher Education http://www.qaa.ac.uk/en/Publications/Documents/SBS-geography-14.pdf (accessed 16/01/2018).

Redclift, M., (1991). The multiple dimensions of sustainable development. Geography, pp.36-42.

Schlosser, P. and Pfirman, S., (2012). Earth science for sustainability. Nature Geoscience, 5(9), pp.587-588. 
Stewart, I., (2016). Sustainable geoscience. Nature Geoscience, 9(4), pp.262-262.

Stewart, I.S. and Gill, J.C., (2017). Social geology_integrating sustainability concepts into Earth sciences. Proceedings of the Geologists' Association, 128(2), pp.165-172. 